\title{
Corporate Water Risk: A Critique of Prevailing Best Practice
}

\author{
Alex Money ${ }^{1}$ \\ ${ }^{1}$ Smith School of Enterprise and the Environment, University of Oxford, Oxford, UK \\ Correspondence: Alex Money, Smith School of Enterprise and the Environment, School of Geography and the \\ Environment, OUCE, South Parks Road, Oxford OX1 3QY, UK. Tel: 44-7961-394-201. E-mail: \\ alex.money@smithschool.ox.ac.uk
}

$\begin{array}{ll}\text { Received: October 29, } 2013 & \text { Accepted: December 13, } 2013 \quad \text { Online Published: February 25, } 2014 \\ \text { doi:10.5539/jms.v4n1p42 } & \text { URL: http://dx.doi.org/10.5539/jms.v4n1p42 }\end{array}$

\begin{abstract}
This paper considers corporate water risk from the perspective of company disclosure. An empirical study, it reviews 6 years' disclosure for 58 companies in the global consumer staples sector. Drawing on a conceptual framework of institutional theory and resource dependence, it examines the disclosed yardsticks by which multinational companies measure their management of water risk. The first empirical study of its kind, it suggests that companies target future improvements that are generally less aspirational than their historic achievements. This appears to be a function of diminishing marginal returns on efficiency investment, exacerbated by a rational reluctance to venture beyond the 'fence line'. The evidence suggests that corporate water risk is increasingly viewed as a political rather than operational issue within the disclosure matrix. Current perceptions of best practice are entrenching a status quo that is fundamentally unfit for purpose given the scale of the challenges that need to be addressed over the rest of this decade, and beyond.
\end{abstract}

Keywords: water risk, corporate disclosure, resource dependence, enterprise, environment

\section{Introduction}

Corporate water risk is a concept in search of consensus.Barton describes it as "a set of material business risks that fall into four broad categories: physical, reputational, regulatory, and litigation risk (Barton, 2010). The significance of these water-related risks varies by sector and by company. Within the academic literature the term is still emergent, but has come to embody those challenges that companies face in ensuring their licence to operate (Sarni, 2011), in an environment of increasing water insecurity; a function of resource scarcity, variability and volatility. Perceptions of water insecurity as a corporate risk issue appear to be increasing, at least in relative terms. The annual Global Risks Report measures changes in the perceptions of 1,000 respondents, selected by the World Economic Forum (WEF) from industry, government, academia and civil society, towards 50 different risks identified by the WEF. In the seventh edition of this report (Howell, 2012), water supply crises were ranked for the first time as a top 5 risk in terms of both likelihood and impact. It appeared on both lists again in the eighth edition (Howell, 2013), and was ranked as the second most severe risk that the business world faces, in terms of impact.

The scale of the challenge is arresting. According to a meta-analysis of independent forecasts compiled by the management consultants McKinsey, the world's estimated need for water infrastructure investment between 2013 and 2030 is US\$ 11.7 trillion (Dobbs \& Pohl, 2013), rising alongside GDP and population growth. Meanwhile, the OECD projects that the average annual world infrastructure expenditure on water between 2020 and 2030 will be US $\$ 1,037$ billion or $1.03 \%$ of world GDP, and more than the combined expenditure on road, rail, telecoms and electricity, over the period (OECD, 2006). Financing this investment in the post-crisis environment presents particular difficulties, given the deterioration in many public sector balance sheets, increased risk aversion by lenders and financial intermediaries, and the relatively small proportion of institutional asset allocation to infrastructure investment, from within the private sector. Under these conditions, it seems likely, if not inevitable, that corporate users of water that are the most exposed to the risks associated with insufficient infrastructure, will have to bear an increasing share of the financial costs that will be incurred to ensure adequate provision. Given that the estimated requirement to 2030 equates to nearly $90 \%$ of the current market capitalisation of the entire S\&P 500 combined, corporate water risk is — or should be - a clear and present issue of concern to companies and long term capital providers. 
Water has unique attributes in terms of a company's operating performance and ESG considerations: as a factor of production it is scarce, unevenly distributed, expensive to transport and has no substitute (Postel, 2000; Seckler, Barker, \& Amarasinghe, 1999). The demand for water is rising worldwide and projections are for continued growth (Butler \& Memon, 2006) due to population expansion and migration, changes in lifestyle and the consequences of climate change (Butler \& Memon, 2006; Pittock \& Lankford, 2010) exacerbating concerns of future water insecurity. The corporate accountability reporting frameworks of a firm's water use are therefore relevant to an extensive set of stakeholders including suppliers, employees, customers, shareholders, regulators and special interests, and this in turn has an important bearing on the firm's wider strategic and policy choices.

Growth rates in the global economy are increasingly asymmetric, with annualised GDP growth of $1.8 \%$ forecast for the so-called advanced economies over the next two years, compared with $5.7 \%$ for the emerging market and developing economies (IMF, 2013). Companies pursing rational, profit-maximising behaviour have sought to expand their activities within these faster-growing regions, and the success of such initiatives have been an important component of the value that has been created for the institutional and private owners of these companies. However, these faster-growing economies often have a relatively smaller stock of infrastructure per capita, and require a relatively larger investment in infrastructure per unit of GDP if these growth rates are to be maintained. Global estimates of required infrastructure investment can underplay the size of the challenge. For example, applying McKinsey's heuristic, Japan's economic growth over the past 18 years would 'justify' infrastructure investment of 3\% of GDP; significantly lower than the 5\% actually spent. Conversely, Brazil's indicative infrastructure spending requirement is $4.8 \%$ of GDP on a comparative annual basis; significantly higher than the $1.5 \%$ actually spent over the past 18 years (Dobbs \& Pohl, 2013). The point can be summarised by the observation that where companies seek higher returns, they may have to accept a higher level of risk.

While there appears to be some common agreement in understanding what corporate water risk means within a macro context, this paper asks whether such risks are appropriately identified at the company level. It is an empirical analysis, and uses information on water risk disclosure by 35 large, listed multinational companies (median market value of US\$ 43 billion) within the consumer staples sector as a proxy. The paper explores four questions. First, have companies identified with the scale of the challenge faced, and is this reflected within their disclosed targets? Second, how do companies evaluate their supply chain within their current disclosure matrix, given the potential returns that might exist on investments 'beyond the fence line'? Third, to what extent do companies recognise corporate water risk as a politicised issue, rather than an operational challenge to be addressed directly? Fourth, does the current dynamic of engagement between companies and investors appear fit for purpose in the context of the challenges faced? Given the interconnections within these questions, a conceptual framework is proposed that rationalises corporate approaches to water risk, and embeds these approaches in an institutional environment that encourages propagation and reinforcement. The next section sets out this framework with reference to the literature.

This paper is framed principally within the literature of resource dependence theory and institutional theory. Other constructs, such as neo-Gramscian theory (Daniel \& Sojamo, 2012) have been applied elsewhere in an attempt to account for the dynamics of governance, power and so forth in corporate disclosure strategies (Levy $\&$ Newell, 2005). However, every approach brings its own limitations, and this paper's attempt at presenting empirical outputs within a clear if parsimonious conceptual framework is a deliberate one.

\subsection{Resource Dependence Theory (RDT)}

Corporate water use is characterised by resource dependence and organisational interdependence. Both local and multinational firms frequently operate within complex supply chains where intermediate goods have an extensive water footprint (Gerbens-Leenes \& Hoekstra, 2008) and account for significant inter-country flows of 'virtual water' (Allen, 2003; Chapagain, Hoekstra, Savenije, \& Gautam, 2006; Hoekstra \& Chapagain, 2008). This creates a requirement for firms to manage their dependencies, both in terms of their organisational relationships, and in terms of environmental uncertainty.

The concept of power - in terms of control over vital resources - is fundamental to resource dependence theory (RDT) (Ulrich \& Barney, 1984); as a strategy, firms seek to reduce others' power over them, while often attempting to increase their power over others (Hillman, Withers, \& Collins, 2009). The associated literature is at least sixty years old (Selznick, 1949; Thompson \& McEwen, 1958; Zald, 1969), although modern RDT can be dated to the publication in 1978 by Pfeffer and Salancik, who proposed a series of actions that firms could engage in to minimize their environmental dependencies (Pfeffer \& Salancik, 1978). Of these, inter-organisational relationships are of particular interest in the context of this paper.

RDT offers a perspective from which to understand inter-organisational engagement (Barringer \& Harrison, 
2000; Hillman, Cannella, \& Paetzold, 2000; Oliver, 1990), by exploring how their formation helps an organisation acquire resources to reduce uncertainty and interdependence (Auster, 1994; Harrigan \& Newman, 1990; Pfeffer \& Salancik, 1978). Inter-organisational relationships differ from mergers in that they provide only partial absorption of the interdependencies (Hillman et al., 2009). Empirical evidence in the literature is consistent with the theory that such relationships gain resources and reduce domestic and international uncertainty (Elg, 2000; Goes \& Park, 1997; Stearns, Hoffman, \& Heide, 1987). The literature also offers evidence that inter-organisational relationships are most likely to develop within the supply chain where mutual interdependencies are strongest, such as between buyers and suppliers (Murray, Kotabe, \& Zhou, 2004; Provan \& Gassenheimer, 1994; Skinner, Donnelly, \& Ivancevich, 1987).

For example, a firm that is a multinational packaged food processor may source its raw material inputs such as wheat, sugar and cocoa from a network of farmers. The interdependencies are strong. Without the network, the food processor has no product to sell. Equally, the food processor is likely to be a major buyer of the farmers' produce, and may even be the sole customer for many. The food processor may seekto strengthen inter-organisational relationships by, for example, paying for farmers to receive training in the latest methods of crop husbandry, or providing low-interest loans for farmers to buy equipment. In exchange, they might require farmers to commit to sell an agreed quantity at an agreed price.

The food processor will also seek to minimise the impact of any perceived vulnerabilities of the farmers on its own operations. Farmers are particularly susceptible to risks associated with water variability, given its materiality as an agricultural input. In principle this variability represents a direct risk for the food processor too, inasmuch as it faces constraints on alternative sources for procurement. Howeverthe food processor may be able to leverage its power to reduce resource dependence, for example by concluding an agreement which commits farmers' collectives to supply a given quantity at a set price, or otherwise face sanction. If the agreement is durable, it enables the food processor to 'lay off' that portion of its waterrisk, and any costs (or possible benefits) as a consequence of water variability are borne by the farmer. If the processor measures corporate water risk from the point at which the raw material input enters the factory, this inter-organisational relationship may have materially lowered the firm's risk profile. Of course, the risk itself is still manifest.

\subsection{Institutional Theory}

The general premise of institutional theory is that firms conform to the expectations of their institutionalised environment in order to gain legitimacy and increase their survival prospects (Meyer \& Rowan, 1977; Scott \& Meyer, 1994). To the extent that firms incorporate the practices and procedures expected of them in response to three identified behavioural pressures (coercive, mimetic and normative), those operating within a common institutional environment will begin to look more similar than they do different (Brown, de Jong, \& Levy, 2009; DiMaggio \& Powell, 1983; Giddens, 1984).

In terms of the three behaviours, coercive pressures may have economic, legal, ethical and discretionary dimensions (Carroll, 1979), while the drivers of mimetic process include poor understanding of a firm's technologies, ambiguous goals, or an uncertain environment (DiMaggio \& Powell, 1983). Normative pressures to homogeneity come from common professional attitudes and approaches that employees in one firm have with those in others. DiMaggio and Powell posit that the rate of 'institutional isomorphism' - that is, homogeneity of organisational structures in an institutional environment-increases when firms are highly dependent on that environment; operate under conditions of uncertainty or ambiguity; or rely heavily on professionals.

For the food processor, coercive pressures on ESG disclosure may come from a legal requirement of regulatory compliance, orfrom activist shareholders, vocal NGO's or other stakeholders demanding that the food processor discloses information about its water use in order to preserve its societal legitimacy. Coercive pressures may also be embedded within social media as a channel for the rapid dissemination of information; given that this can have a material impact on corporate reputation. Coercive pressures can impose common societal expectations across competing firms about how inputs should be combined and deployed in production (Oliver, 1997). Firms may model their CSR disclosure on those they perceive to be more legitimate or successful (DiMaggio \& Powell, 1983; Kostova, Roth, \& Dacin, 2008; Rao \& Sivakumar, 1999).

Thespecific uses of water within the food processor's operations may be complex and difficult for non-specialists to understand, encouraging mimetic process. Common metrics that simplify the information for stakeholders such as financial analysts may be widely adopted by other food processors, creating path dependency. Goals regarding water risk management can also be ambiguous. One firm may target reducing the absolute amount of water being used by changing its mix of business activities rather than by improving efficiency of water use; while anothermay target improved efficiency while accepting absolute consumption may 
rise. Reconciling these different approaches may require the adoption of a 'lowest common denominator' in terms of disclosure. Also, uncertainty in terms of water risk may be driven by various factors, including demographic dynamics, volatility in economic activity, and variability as a consequence of climate change. As uncertainty increases, so does mimetic process.

Normative behaviours are shaped by the relatively small number of corporate water risk specialists that exist, and the collegiate characteristics of the wider ESG profession. Their interchange of knowledge, beliefs and approaches to best practice may primarily occur during industry specific conferences and other collective events. This may encourage homogeneity in attitudes over how water risk should best be understood and communicated to other stakeholders. If the ESG disclosure specialist at the food processor firm leaves, they likely will be replaced by someone with a similar background and experience. Inasmuch as the new hire also has a similar attitude to disclosure, the existing approach gains further institutional legitimacy. And where the new hire has a different attitude, they may push for a change in approach, particularly if they come from a firm that is perceived to be more legitimate or successful.

In summary, resource dependence theory provides some insight into corporate water risk in context, and the motivations that might drive individual firms' behaviour on disclosure. Institutional theory frames this behaviour in terms of organisational structure and perceptions of legitimacy. This conceptual framework articulates how a firm's self-interested actions in managing corporate water risk can become embedded into wider ESG disclosure that is homogenised, widely accepted, and considered best practice.

\section{Method}

The empirical analysis in this paper focuses on firms' use of water efficiency targets. The sample is drawn from the 58 firms in the consumer staples sector identified by the Carbon Disclosure Project (CDP) in their second annual Water Disclosure report (CDP, 2011). Using the FTSE Global Equity Index of the world's 500 largest quoted companies by market capitalisation (Q4 2010 values), the CDP invited at total of 315 constituent firms that it judged to be in either water-intensive sectors, or in sectors that were sensitive to water issues in their supply chain, to respond to a questionnaire on water disclosure. A total of 190 of these firms responded ( $60 \%$ response rate). By sector, 37 firms in the Global 500 consumer staples sector were invited to respond, and $27 \mathrm{did}$ so (73\% response rate). In addition to the Global 500 index, the CDP invited 54 of the 100 largest firms in Australia and 56 of the 100 largest firms in South Africa to respond to the questionnaire. Of the 5 consumer staples sector companies in Australia 3 responded (60\% response rate) and of the 13 consumer staples sector companies in South Africa, 6 responded (46\% response rate). In addition, another 6 consumer staples companies that were not originally invited to respond by the CDP did so voluntarily. This yields a total of 61 consumer staples companies (37 in Global 500, 18 in country lists and 6 voluntary respondents) of which 3 appear in both the Global 500 and country lists, so eliminating double counting results in a sample size of 58 companies.

Consumer staples comprise the following sub industries: beverages; food \& staples retailing; food products; household products; personal products; and tobacco. The decision to base the sample on firms from the consumer staples sector was taken for four reasons. First, the high response rate of the sector to the CDP Water Disclosure questionnaires offered a relatively rich source of supplementary and corroborative information. Second, the firms in the sector have primary listings in 13 separate countries, allowing a more cohesive interpretation of the findings within an international context. Third, the sector offered a good balance between local and multinational firms, given CDP's country focus on South Africa and Australia. Fourth, the consumer staples sector is characterised by complex supply chains, suggesting relatively high organisational interdependencies. However the approach used to evaluate disclosure is not sector-specific and could be extended to firms in any of the other sectors in the CDP report (consumer discretionary; energy; health care; industrials; information technology; materials; and utilities), or indeed to companies more generally.

Between September 2011 and January 2012, the CSR reports, annual reports and other public filings for the previous 6 years were reviewed for each of the 58 firms in the sample. Only data from publically accessible online documents was included. After an initial review of the information, a template was created in order to capture data in a systematic, rigorous and replicable manner.

The template identified each firm by its name, the website address from which data has been collected, the date of collection, and its response status to the CDP questionnaire. It recorded whether a CSR or sustainability report was available for the firm, and the latest year for which it was available. Using the Global Reporting Initiative's G3.1 guidelines (Global Reporting Initiative, 2011) the template captured, where available, structured firm-level data on water withdrawals (EN 8); regions affected by withdrawal (EN 9); the amount of water reused (EN 10); and total water discharged (EN 21). It also collected data on the type of water source, and whether a metric has 
been provided for water efficiency. The template also recorded the extent to which the current disclosure could be reconciled with what had been disclosed in prior years. Further, the template captured semi-structured information as disclosed by the firm, including the target(s) it had set with regard to water use; the tools that it used to measure water risk; the financial impact of mitigation or adaptation strategies; and its description of the risks and/or opportunities it faced in terms of water use. For the 42 companies in the sample that completed the CDP Water Disclosure questionnaire and allowed their responses to be made public, the information from their CSR reports was cross-referenced and verified, inconsistencies noted, and data in the template was augmented with supplementary disclosure in the CDP filing. In addition, data from a Bloomberg terminal was used to collate financial information for all 58 firms in the sample including market capitalisation, changes in reported revenue over the previous 5 years (as a proxy for firm performance), and changes in reported gross profit margin over the previous 5 years (as a proxy for firm efficiency). The financial data was collected at the end of the fourth quarter of 2011.

In order to use water efficiency disclosure as a proxy for CSR policy choice, each firm's reported water efficiency ratio for the previous 6 years was tabulated, and a definition noted of the metric used. This was most commonly reported as the number of units of water consumed per unit of product, or equivalent. For firms in the sample where 6 years of data was not available, data was recorded for whatever years were available. In total, at least 2 comparative data points were available for 33 firms of the 58 in the sample (57\%). Using the tabulated data, the annualised growth rate (CAGR) of changes in the efficiency ratio were calculated for 1, 2, 3, 4 and 5 year periods for each firm, and recorded together with the mean. Each firm's reported water efficiency target was similarly tabulated, based on the most recent year of available disclosure. This was recorded as a single CAGR number, based on the proposed efficiency target and the number of years the company had set itself to achieve it by. For example if a firm had set a target of a $20 \%$ improvement in its efficiency ratio from current levels over the next 10 years, this would be calculated as $0.8^{\wedge}(1 / 10)-1=$ a $2.21 \%$ annualised target improvement.

A consolidated summary of the data gathered is accessible online: http://bit.ly/IgV2Hs.

The original 58 firm sample included firms from 13 countries; however once adjusted to reflect available for efficiency disclosure, the sample was reduced to 35 firms from 10 countries, as Table 1 shows. Firms with their headquarters in either the USA or the UK combined comprised $45 \%$ of the 58 firm sample, but $57 \%$ of the 35 firm sample. In contrast, firms from South Africa accounted for $19 \%$ of the 58 firm sample, but a single one of the 35 firm sample: therefore the inclusion of efficiency disclosure as a screen had a material effect on various characteristics of the sample. The possible implications of this, for example in terms of institutional shareholder engagement (Clark \& Hebb, 2005) are not explored in detail in this paper, but would be an important area for further research.

Nonetheless, the adjusted sample can be characterised as comprising large, economically important firms, operating in a complex, multidimensional governance environment. Their median market capitalisation is US\$42 billion, and the total reported water used in their operations is over 1.5 trillion litres per year, equating to over half a litre per day for every human being on the planet. The companies own many of the world's most familiar consumer brands, and the collective distribution footprint of their products extends to almost every country in the world. For these reasons the activities of the sample firms-including their ESG strategy and policy choices - are of interest to a broad range of institutional stakeholders.

Table 1. Consumer staples company sample

\begin{tabular}{llllll}
\hline Name & Country & Abstraction & CDP & Historic & Target \\
\hline Foster's & AU & 23,155 & DP & $-5.69 \%$ & $-2.60 \%$ \\
Woolworths & AU & 2,970 & AQ & $-2.41 \%$ & $-2.07 \%$ \\
AB Inbev & BE & 157,800 & AQ & $-7.05 \%$ & $-6.63 \%$ \\
Carlsberg & DK & 38,325 & NP & $-4.01 \%$ & $-2.94 \%$ \\
Carrefour & FR & 21,900 & NP & $-9.36 \%$ & \\
Danone & FR & 34,850 & AQ & $-9.29 \%$ & $-3.47 \%$ \\
L'Oreal & FR & 2,956 & AQ & $-4.08 \%$ & $-6.70 \%$ \\
Pernod Ricard & FR & 6,155 & AQ & $-6.36 \%$ & $-2.09 \%$ \\
Japan Tobacco & JP & 6,346 & NR & $-9.42 \%$ & $-2.52 \%$ \\
Kao Corp & JP & 11,617 & AQ & $-7.84 \%$ & $-2.35 \%$ \\
Kirin & JP & 89,300 & AQ & $-3.26 \%$ & $-1.74 \%$ \\
WalMex & MX & 5,083 & NP & $-8.90 \%$ & $-5.43 \%$ \\
\hline
\end{tabular}




\begin{tabular}{llllll}
\hline Heineken & NL & 83,000 & AQ & $-3.59 \%$ & $-1.64 \%$ \\
Unilever & NL & 56,610 & AQ & $-5.95 \%$ & $-11.85 \%$ \\
Nestle & CH & 144,000 & AQ & $-6.31 \%$ & $-3.20 \%$ \\
British American Tobacco & UK & 4,481 & AQ & $-8.04 \%$ & $-2.84 \%$ \\
Diageo & UK & 23,137 & AQ & $-5.26 \%$ & $-4.36 \%$ \\
Imperial Tobacco & UK & 1,602 & AQ & $-1.24 \%$ & \\
Reckitt Benkiser & UK & 5,300 & AQ & $-6.21 \%$ & \\
SAB Miller & UK & 73,100 & AQ & $-0.84 \%$ & $-4.03 \%$ \\
Altria Group & US & 3,566 & AQ & $-11.63 \%$ & $-3.19 \%$ \\
Archer Daniels Midland & US & & NR & & $-1.61 \%$ \\
Coca Cola & US & 309,000 & AQ & $-2.75 \%$ & $-2.75 \%$ \\
Colgate Palmolive & US & 5,400 & AQ & $-7.89 \%$ & $-4.25 \%$ \\
General Mills & US & 10,900 & AQ & $-1.90 \%$ & $-2.45 \%$ \\
Kellogg & US & 12,530 & AQ & $-3.14 \%$ & $-2.21 \%$ \\
Kimberley Clark & US & 129,700 & AQ & $0.64 \%$ & $-3.80 \%$ \\
Kraft & US & & DP & & $-3.20 \%$ \\
PepsiCo & US & 106,000 & AQ & $-6.21 \%$ & $-2.45 \%$ \\
Philip Morris Intl. & US & 4,350 & AQ & $-2.52 \%$ & $-4.36 \%$ \\
Procter \& Gamble & US & 79,999 & AQ & $-14.52 \%$ & $-4.36 \%$ \\
Reynolds American & US & 2,019 & AQ & $-22.94 \%$ & \\
McCormick & US & 900 & AQ & $-7.25 \%$ & $-1.74 \%$ \\
Molson Coors & US & 23,973 & AQ & $0.12 \%$ & $-3.88 \%$ \\
HJ Heinz & US & 29,790 & $-3.11 \%$ & $-2.21 \%$ \\
\hline
\end{tabular}

$\underline{\text { Notes }}$

1. Country: $\mathrm{AU}=$ Australia, $\mathrm{BE}=$ Belgium, $\mathrm{DK}=$ Denmark, $\mathrm{FR}=$ France, $\mathrm{JP}=$ Japan, $\mathrm{MX}=$ Mexico, $\mathrm{NL}=\mathrm{Netherlands}, \mathrm{CH}=$ Switzerland, UK = United Kingdom, US = USA.

2. Mkt Cap: Market Capitalisation in US\$ millions.

3. Abstraction: Reported volume of water abstracted p.a. in thousands of cubic meters (' $000 \mathrm{~m}^{3}$ ).

4. CDP: CDP Water disclosure status. $\mathrm{AQ}=$ Answered Questionnaire, $\mathrm{DP}=$ Declined to Participate, $\mathrm{NP}=$ Non Public Response, $\mathrm{NR}=$ No Response, $\mathrm{NA}=$ Not Invited by CDP.

5. Historic: Average Annualised Change in Disclosed Water Efficiency for 1,2,3,4 and 5 years.

6. Target: Required Annualised Change in Water Efficiency to achieve disclosed target.

\section{Results}

\subsection{Historic Efficiency}

As a proxy for historic efficiency, the average annualised change in the disclosed amount of water used per unit of product for the previous 5 years is used. The data is shown graphically in Figure 1: 


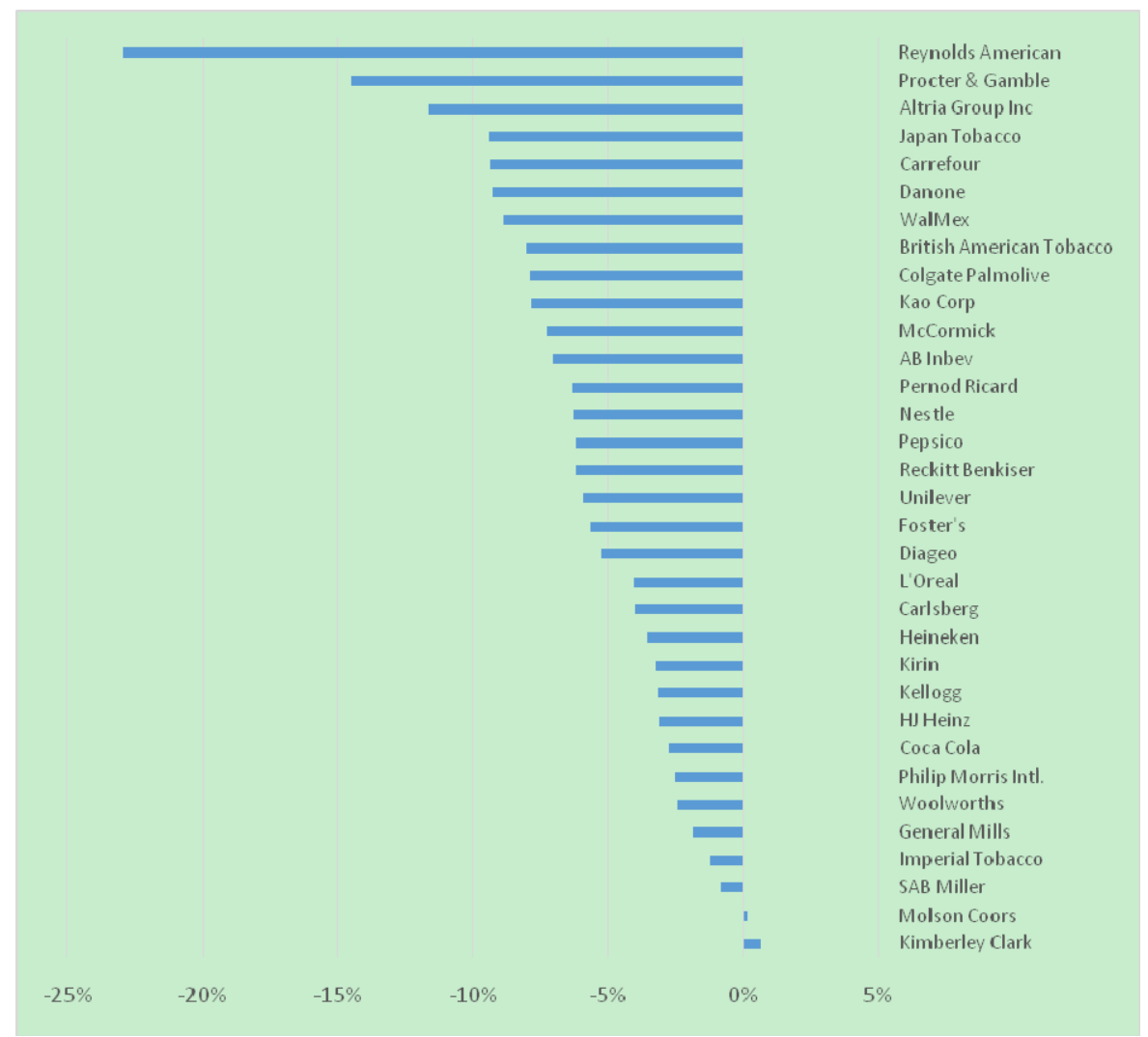

Figure 1. Annualised historic change in water efficiency

Of the 33 companies disclosing a least two data points of historic change in water efficiency, $31(94 \%)$ reported a reduction in the volume of water used per unit of production. The average reduction in water/ unit for the sample was $-5.9 \%$ (median $-5.9 \%$ ).

\subsection{Target Efficiency}

As a proxy for target efficiency, the compound annual growth rate that is necessary for the company to achieve its disclosed efficiency target over the timeframe it has chosen, is used. The data is shown in Figure 2: 


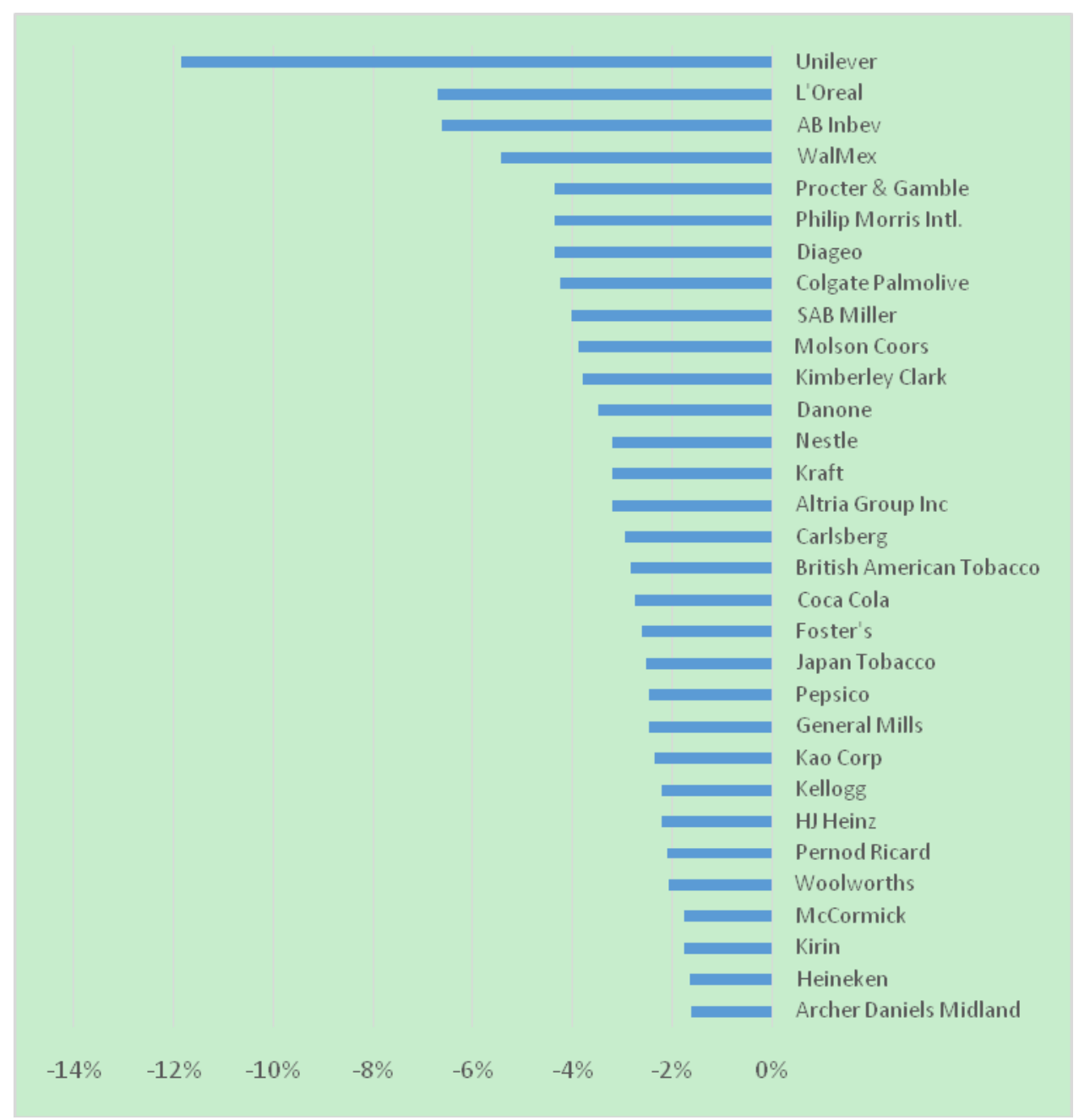

Figure 2. CAGR in water efficiency required to achieve target

Of the 31 companies disclosing a water efficiency target, all targeted an improvement in efficiency compared to current levels. The average improvement in targeted water/unit for the sample was $-3.6 \%$ (median $-2.9 \%$ ). That is, the targeted improvement in water efficiency is 230 basis points lower on average than the actual historic improvement in efficiency. In terms of the median, the targeted improvement is some 300 basis points lower than the historic improvement.

\subsection{Aspiration Multiple}

For each firm where the data is available, the Target Efficiency is divided by the Historic Efficiency to derive an "Aspiration Multiple" (ASMUL). An ASMUL of more than 1 indicates that a firm aspires to deliver water efficiencies in the future at a greater rate than it has in the past. An ASMUL of less than 1 indicates that a firm aspires to deliver water efficiencies in the future at a lesser rate that it has in the past. Adjusting for available data and excluding firms who have historically become more inefficient yields a sample size of 26 companies. Their ASUMLs are shown in Figure 3. 


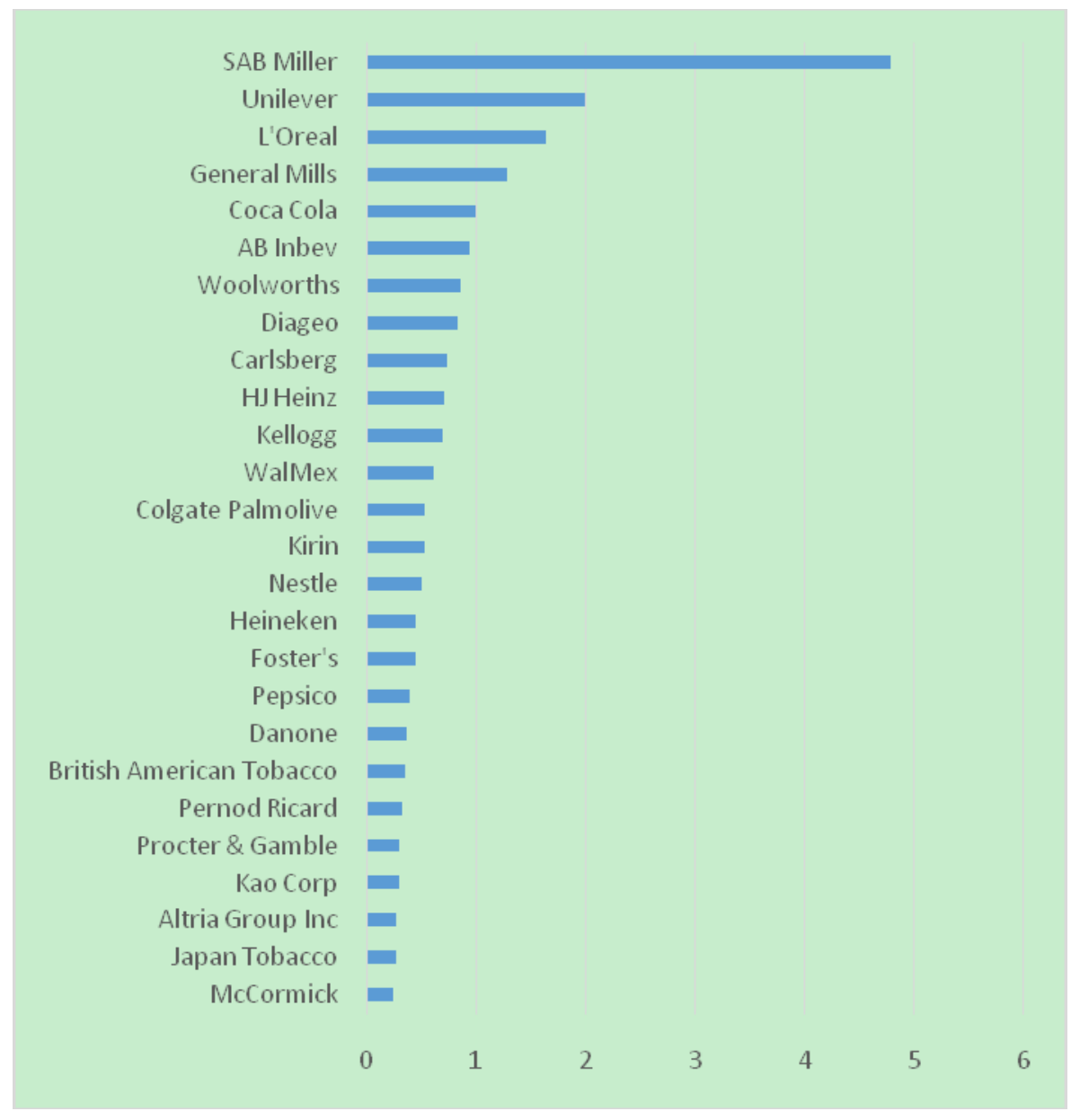

Figure 3. Water efficiency aspiration multiples (ASMULs)

Of the 27 firms, $4(15 \%)$ have an ASMUL of greater than 1.0. The mean ASMUL for the sample is $0.85 \mathrm{x}$, and the median is $0.54 \mathrm{x}$. The median value is more meaningful. If the two firms with the highest and lowest ASMULs are excluded, the adjusted mean falls to $0.66 \mathrm{x}$. In the case of the firm with the highest ASMUL, this is based on a historic annualised efficiency improvement of just $-0.84 \%$ compared to the average for the sample of $-6.0 \%$. That is, the ASMUL value has been heavily influenced by the low denominator.

In summary, it is possible to infer from the ASMUL data that the majority of firms in the sample are targeting a materially lower rate of improvement in their efficiency of water use in the future, compared to what they have achieved historically.

\subsection{Descriptive Statistics}

Descriptive statistics associated with the analysis are presented in Table 2. Five year sales and gross profit margins have been included as proxies of firm performance and efficiency, respectively. This paper seeks to build rather than test theory, and the relatively small sample size - a function of the resources required to compile the primary data-precludes the performance of any meaningful statistical analysis. However the empirical framework has been designed to be both easily replicable and highly scalable. A broader and deeper sample would provide the opportunity to test theory using ASMUL, historic efficiency and target efficiency as possible dependent variables. 
Table 2. Descriptive statistics

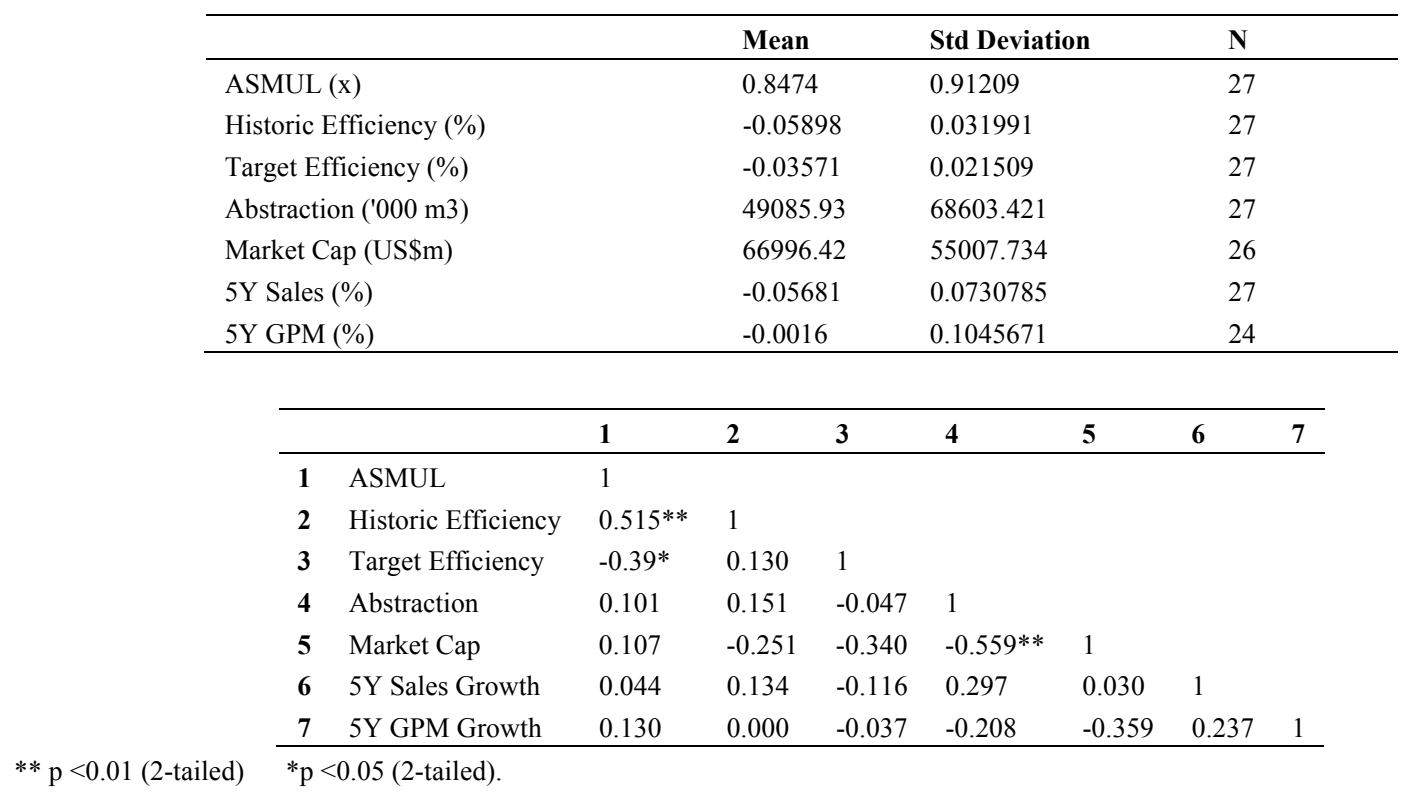

\subsection{Marginal Efficiency}

Figure 4 plots the average CAGR of historic efficiency improvements over 1, 2, 3, 4 and 5 years for the sample. It shows that on average, the highest efficiency improvement is achieved in the first year, decreasing in each of the subsequent years. This is consistent with the theory of diminishing returns on efficiency investment; as well as the argument that ASMULs will inevitably fall over time.

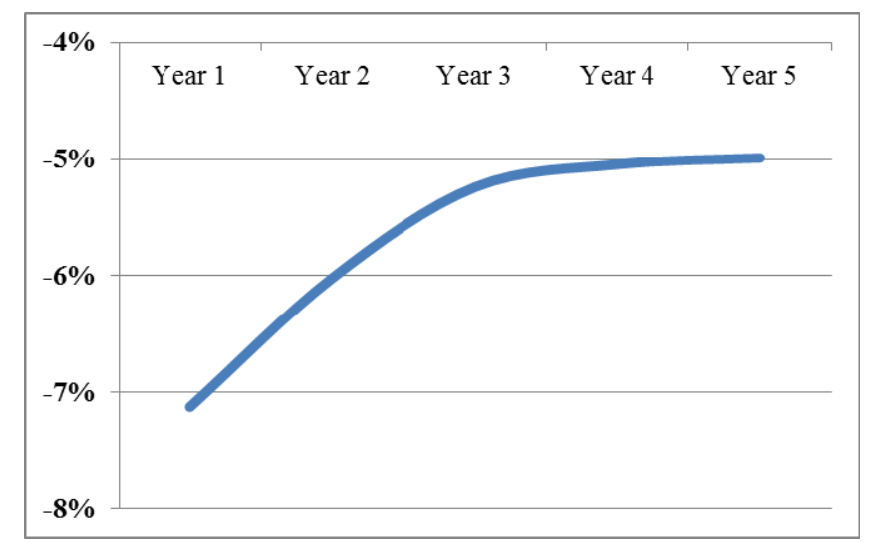

Figure 4. CAGR improvements in historic water efficiency for consumer staples sample

\section{Discussion}

Changes in the form and function of narrative disclosure over time point to an increasing emphasis by firms on the measurement and management of corporate water risk. However the analysis in this paper suggests that the majority of firms in the sample are currently targeting a materially lower rate of improvement in their efficiency of water use in the future, compared to what they have achieved historically. This is generally at odds with the 'tone' of the recent narrative on water resource management in the firms' CSR disclosure. But viewed through the lenses of RDT and institutional theory, this apparent variance between what is being said and what is being done reflects entirely rational behaviour on the part of firms, in response to complexity, interdependence and uncertainty. The question is whether the status quo of the prevailing position can be maintained.

\subsection{Resource Dependence and Rational Behaviour}

From an RDT perspective, as a company identifies the threat of dependence, it will seek to mitigate the threat as 
expeditiously as possible without drawing unnecessary attention to it. If the threat is within the company's direct control, such as usage of water within its own operations, management of discharge, replenishment within the watershed etc., the company has greatest capacity to mitigate the threat, and will do so where the cost of mitigation is perceived to be lower than the benefit from mitigation. As the company's ability to incrementally reduce the threat via direct action lessens, it may give greater consideration to the scope that it has to reduce threats associated with its dependency on its supply chain. This is consistent with the broader literature on corporate water risk practice (Morrison, Schulte, \& Schenck, 2010).

Importantly RDT does not necessarily require the company to be interested in reducing any supplier's own dependence on water, but rather the company's dependence on that supplier. For consumer staples companies such as food and beverage manufacturers, suppliers might include agricultural commodity producers with a significant water footprint. To mitigate the implicit threat of the supplier's water risk exposure combined with the company's dependence on that supplier for its raw material inputs, the company might rationally seek to exclude any form of explicit management or measurement of the supplier's water usage within its own quantitative disclosure, despite - or more likely because of - its recognition of the significance of that usage.

However, the company will still recognisethat the threat exists within the minds of its stakeholders, including shareholders, consumers and others, regarding water risk in the supply chain.In order to mitigate this threat, the company might emphasise in its narrative disclosure, inter alia, the importance it ascribes to working with its supply chain to reduce usage, improve efficiency, support community access and so on. This is anticipated in RDT literature as a rational response by companies, and is consistent with the observed outputs in this study where narrative disclosure on corporate water risk has increased in breadth and scope (Daniel \& Sojamo, 2012), without a corresponding expansion of quantitative disclosure.

Indeed, similar observations are widely evident within the broader literature, and over time these have coalesced into a call for better corporate disclosure of water risks "beyond the fence line". This approach exhorts companies to take a more holistic approach to the watershed, and to engage local participation in the collective management of water resources. Contemporary literature identifies "a number of leading companies" (WBCSD, 2013) that have started to develop this approach, while outlining the challenges that businesses face in its adoption, including a lack of established governance systems, weak participatory process, and the "difficulty of getting internal high-level commitment in the absence of clear quantifiable benefits" (ibid.).

Applying RDT, the benefits to companies of such forms of engagement become clearer and more quantifiable in proportion to the perceived threat of interdependency. In fact, (Pfeffer \& Salancik, 1978) identified political action as one response that firms could engage in to minimize their environmental dependencies. This approach might eliminate some of the difficulties that businesses associate with governance and participation, albeit by engaging at a level removed from the watershed. Anecdotal evidence for the increasing popularity of companies politicising their engagement with water risk canbe gleaned from the website content of the CEO Water Mandate, which, according to its mission statement, involves "mobilising a critical mass of business leaders to advance water sustainability solutions - in partnership with the United Nations, civil society organisations, governments and other stakeholders" (Mandate, 2013).

The 2030 Water Resources Group goes further, claiming to work with governments "on a comprehensive water reform strategy" and supporting its implementation (WRG, 2013). It includes India, Jordon, Mexico, Mongolia and South Africa as its government partners, with Nestle, PepsiCo, SABMiller and Coca-Cola as private sector partners (ibid). These companies are all members of the consumer staples sample in this report. Each has complex interdependencies within its supply chain; each produces extensive narrative disclosure on corporate water risk; and none quantifies the impact of water use outside their direct operations, within their disclosure. As such they exhibit entirely rational behaviour as anticipated by RDT.

\subsection{Institutional Theory and Isomorphic Behaviour}

The empirical findings of this study are wholly consistent with thevarious coercive, mimetic and normative behaviours associated with institutional theory. Companies seek to create and maintain their legitimacy through practices and procedures that embed isomorphism. This contributes to the preservation of a status quo in which most institutional actors are satisfied in the short term, but at the cost of delaying, deferring or denying the steps that are necessary to mitigate corporate water risk in the longer term. So, while resource dependence shapes the tone and tangent of corporate disclosure and engagement with water risk; it is through the lens of institutional isomorphism that the variance between what is being said and what is being done can be most clearly understood. The contextual attributes of coercion, mimetic process and normative behaviour are discussed briefly below. 


\subsection{Coercive Pressure}

The companies chosen for this paper were drawn from the consumer staples sector of the CDP Water Disclosure Report. The sample was selected to represent exemplars of best-in-class disclosers of corporate water risk. And while the CDP's objectives in terms of seeking greater transparency in corporate water disclosure are laudable, there is evidence of coercive pressure on firmsfrom the very first page of their latest Water Disclosure Report, which states that the initiative has the formal support of 470 investors representing US\$ 50 trillion in assets (CDP, 2012). Although the nature of this support is not explicitly set out in the report, the impression conveyed in the report's narrative is that the CDP survey comprises questions that their owners want-and expect-answers to. A reasonable interpretation of this narrative might be that there are implicit if unstated consequences for companies who make a decision not to participate in the survey.

The motivations for the CDP to deliver a high rate of participation in its surveys are self-evident. The credibility of its research is a function of its perceived representativeness. As a voluntary form of disclosure that requires time and effort on the part of companies to complete a questionnaire, the CDP applies a nuanced combination of incentives and sanctions in order to drive participation. The extent to which these measures are effective depend on the impact that companies perceive the report has on their actual and potential investor base, and the level of scrutiny that will be applied to their responses.In practice, while the 470 investors in question undeniably husband a large quantum of assets, the thresholds set for them to become signatories are not especially onerous. Any financial institution managing assets may become a CDP signatory at no charge, and on becoming a signatory, can access all company responses to the questionnaires they endorse. In addition they receive "public recognition of [their] commitment to engaging with companies on the issues of climate change and water" (CDP, n.d.).

There are obvious interdependencies between the CDP, responding companies and signatory investors. For the CDP to preserve or enhance its authoritative standing amongst disclosing companies, it is important that it is seen to carry a significant quorum of their investor base as signatories. It is in turn logical for the CDP to set thresholds for membership that can be achieved and maintained fairly easily. Meanwhile for the investor signatory, membership of the CDP may be seen as a source of distinction and differentiation, and carry a value to the institution in terms of the competitive marketplace. These interdependencies combine to drive coercive pressure on companies to disclose, although the magnitude of this pressure should not be overstated. In their latest report, the CDP records a response rate of $60 \%$ to its questionnaire, which is unchanged on the prior year (CDP, 2013).

Coercive pressures on companies to disclose their exposure to water risk have been explored more widely in the literature (Barton, 2010; Hepworth \& Orr, 2013). Reputational water risks garnered in the course of conducting 'business as usual' can affect a company's brand value and market share (Orr \& Cartwright, 2010), which in turn have potentially long-term financial implications (WBCSD, 2013). Companies have responded to pressures to maintain a so-called social licence to operate (Hepworth \& Orr, 2013; Sarni, 2011), and as discussed previously corporate water risk is frequently broken out in the literature into four components: physical, reputational, regulatory, and litigation risk (Barton, 2010). Coercive pressures from a physical, regulatory or litigation risk perspective are self-evidently a function of doing business; it is this paper's contention that it is the pressure on corporate reputation that principally shapes the form and function of water risk disclosure.

\subsection{Mimetic Process}

If coercive pressure helps to explain companies' motivations for disclosing water risk, the nature of their disclosure is better understood with reference to mimetic process. In their development of institutional theory, (DiMaggio \& Powell, 1983) identified the drivers of mimetic process to include a poor understanding of a firm's technologies, ambiguous goals, or an uncertain environment. These drivers are contextually appropriate to water risk disclosure.

Definitions of corporate water risk are themselves contested, and so the basis of measurement and disclosure similarly lacks consensus. As a factor of production, water is perhaps uniquely complicated, given the considerations of supply, access, discharge and replenishment, which are each sensitive to spatial, temporal, political, economic and even philosophical heterogeneity. As a result a holistic understanding of corporate water risk is often elusive within companies themselves, let alone external stakeholders. And where, as in the case of this study, each company operates in multiple geographies and produces a diverse range of products, the level of complexity increases exponentially. Such circumstances inevitably result in a poor understanding of a company's true water risk exposure and it is rational for companies to look to their peers as benchmarks for disclosure. 
This complexity has an inevitable impact on the formulation of corporate strategy, particularly where that strategy concerns water resource management. RDT suggests that it is rational for companies to emphasise their narrative disclosure when considering wider supply chain impacts, but for operations within their direct control, measurement and management of water risk is a threat mitigation strategy. However, this begs the question as to what the most appropriate goals are for this mitigation. For example, a goal to reduce water use in absolute terms might drive efficiency in the short term, but would potentially impede revenue growth, which will likely be another, higher priority, strategic objective. Moreover, water's complexity as a factor of production will also contribute to goal ambiguity.

The literature on corporate water risk in recent years has increasingly been framed in the context of an uncertain operating environment. Economic geographers cite various dimensions to this uncertainty, including climate change (Butler \& Memon, 2006; Pittock \& Lankford, 2010), demographics and urbanisation (Baker \& Toft, 2003), and the energy-food-water-climate nexus (Waughray, 2011). Inasmuch as uncertainty is a proxy for risk, these dynamics may have played a greater part in determining corporate strategies of avoidance, mitigation and adoption, but in practical terms the vulnerabilities remain, as evidenced for example by Dell Computer, following the floods in Thailand in 2012. An uncertain environment creates greater reasonsfor companies to 'stay with the pack' in terms of strategy and disclosure, contributing to mimetic process.

This paper identifies evidence of mimetic process in various aspects of corporate water risk disclosure. For example, of the firms disclosing quantitative data on water use, water efficiency is the only metric that was used by the majority of companies, possibly because at a superficial level, it is the most straightforward to measure: units of water used per unit of output. However in the course of interrogating the longitudinal data, it became evident that companies do not apply this benchmark consistently or comparably. Several firms exclude various facilities for which they say data is unavailable. Some firms exclude the operations of businesses which they have recently acquired. Others change the basis of calculation from one year to the next, typically on the pretext that they have improved their (internal and undisclosed) methodology of calculation. Still others adjust for replenishment and reuse. The reasons for thesevariations are clear, and relate to the drivers of mimetic process itself: poor understanding, goal ambiguity and operational uncertainty.

The point that this raises is that while generic approaches to measuring and managing water risk may become widely adopted in response to mimetic process and augmented by perceptions of best practice, the institutional legitimacy conferred by such adoption may not be justified at any practical level. In other words, the status quo that emerges from the pursuit of 'best practice' corporate water risk disclosure, might in fact unintentionally entrench poor understanding, goal ambiguity and operational uncertainty that are characteristics of mimetic process.

\subsection{Normative Behaviour}

An entrenched status quo that is unfit for purpose may be one outcome from the headlong pursuit of best practice in water risk disclosure, but it is not an inevitable outcome. Various stakeholders with an interest in this disclosure are in principle empowered to challenge the approaches taken by companies, and exhort them to change. These include activist and socially responsible investment (SRI) funds, several of which are owned and managed by large institutional investors. Hebb describes the power that defined benefit pension funds can also bring to this process, due to their long term investment time horizon, diverse ownership and international exposure (Hebb, 2008).

The literature on the correlation between a company's ESG performance and its long term financial performance is as broad as it deep (see e.g., Peloza (2009) for a summary), and the conclusions are contested. Equally ambiguous, however, are the motivations of SRI analysts who are tasked with interpreting ESG information in order to evaluate companies. The typical outcome of this process is a relative ranking, where company $\mathrm{X}$ can be judged as qualitatively superior to company $\mathrm{Y}$ in terms of ESG disclosure, which is often based on a quantitative evaluation of the ESG disclosure metrics applied by company $\mathrm{X}$ and $\mathrm{Y}$.

It is often difficult to compare companies on a like-for-like basis in this way; indeed it is why standards such as the Global Reporting Initiative were developed, although none of these are universally adopted. As a consequence SRI analysts might find themselves spending the majority of their time attempting to reconcile different disclosure formats in order to normalise the data for comparability. In these circumstances, it is understandable that the investment firms where these analysts work will enjoin companies to develop common metrics and standards.

An unintentional consequence of companies responding to these demands may be that in the quest to provide granular and ostensibly comparable quantitative data, the qualitative value of this data is compromised. For 
example, companies might produce a measure of their water efficiency that SRI analysts can benchmark against other companies, but, for the reasons discussed above, the metric itself is fundamentally comprised: that is, accuracy is traded in exchange for precision. DiMaggio and Powell (1983) describe normative pressures to homogeneity as coming from common professional attitudes and approaches that employees in one firm have with those in others. So for example the CSR specialist at the company is motivated to produce an efficiency metric, firstly because that is what is asked for by the investor, and secondly because he knows that is what his CSR colleagues in other companies are producing also. Meanwhile the SRI analyst at the investment firm is motivated to ask companies for an efficiency metric, firstly because it offers a comparativedata set, and secondly because she knows this is what her SRI colleagues at other investment firms are using too.

Normative behaviour on the part of both company and investor representatives is often reinforced by third parties acting as consultants or information aggregators, who have unambiguous commercial incentives to mediate engagement between the company and the investor. As these third parties increase in size and influence, thestatus quo might become yet further entrenched and legitimised.

\subsection{Summary: Resource Dependence and Institutional Theory}

Amongst the outputs of this analysis of corporate water risk disclosure, there are four observations to highlight. First, the sample companies have historically achieved greater annualised improvements in their own water efficiency than the targets that they have set out for the future, i.e., ASMULs are declining. Second, the sample companies appear to exhibit diminishing marginal returns on efficiency investment, due to restricting this investment to their own operations rather than the supply chain. Third, the sample companies have expanded their narrative disclosure on water risk and are increasingly politicising their engagement. Fourth, a status quo of perceived best practice disclosure of corporate water risk is emerging, reinforced by companies, investors and third parties.

These observed outputs are congruent with the theoretical framework set out in this paper. First, companies seek to mitigate the threat of their resource dependence. It is logical to invest on reducing dependence on water until the point where the marginal benefit of reduced dependence is equal to the marginal cost of that investment. As the marginal benefit falls and the marginal cost rises, the aspiration multiple (ASMUL) will decline. Second, companies are highly interdependent on their supply chain, which in turn presents vulnerabilities. Exposing the level of water risk in the supply chain without having the control necessary to reduce that risk could make this vulnerability even more visible. Instead, it is rational to be highly cautious about the extent of direct investment within the supply chain, given that investment brings exposure. Alternative approaches to mitigate the threat include public and political engagement on the positive activities being undertaken by the company.

Corporate responses of this type to the threat of resource dependence are only sustainable if these responses are considered legitimate within an institutional framework. Companies face coercive pressure to articulate their responses through corporate water risk disclosure. The format of narrative disclosure allows companies to emphasise aspects of their threat mitigation strategy selectively, and as the threats have expanded, so too has their narrative disclosure. Operating in an environment of complexity, ambiguity and uncertainty has encouraged companies to take their cues from their peers, and mimetic process has created a received wisdom of what is best practice in corporate water risk disclosure. Sources that might traditionally be expected to challenge this received wisdom, such as shareholders and other stakeholders, have instead responded to normative behavioural pressures that have, crudely speaking, cherished form over substance. As a result, a status quo has become entrenched, acquiring a legitimacy that is arguably unjustified given what is at stake.

\section{Conclusion}

Current approaches to corporate water risk disclosure are fundamentally unsatisfactory when applied to understand the scale of the challenges faced. Efficiency targets offer a superficially attractive benchmark of improvements in company performance, but diminishing marginal returns on efficiency investment will inevitably render such measures progressively less meaningful. A more useful approach would incorporate targets 'beyond the fence line', but companies behaving rationally are unlikely to expose themselves to the execution risk that this implies; notwithstanding the momentum towards greater transparency identified in the literature (Meyer, 2010).

This paper raises questions on the quality of corporate engagement with water risk. Institutionalism and resource dependence combine to render companies risk averse and path dependent in terms of their disclosure. Complexity, uncertainty and normative pressures appear to entrench the status quo. And while company management are likely to be cognisant of the operational consequences of physical, reputational, regulatory, and litigation issues, their response - inasmuch as the disclosure is a barometer-appears to focus on socialising 
water risk as concept amongst a broad group of external stakeholders. The fact is that the challenges faced are granular rather than conceptual, and this approach is diffuse, often incoherent, and fundamentally unfit for purpose.

So what will break the status quo? The consequences of inadequate investment in mitigating water risk would probably eventually manifest themselves in a company's financial statements, although the timing and impact of this is obviously difficult to call. However, if the OECD projections are accurate, there is a requirement for some US $\$ 100$ billion to be invested in water infrastructure every yearfor a decade between 2020 and 2030. These are difficult numbers to contextualise, but it seems reasonable to assume that the absence of this investment will have a very real impact on the societies where this infrastructure is most needed.

Who is capable of making such investments, and what is their motivation to do so? To the extent that future water infrastructure is financed by companies' balance sheets, this is the real corporate water risk. While risk aversion and path dependence might be responsible for disclosure that is not fit for purpose today, these same behavioural paths may be the catalysts for a new form of corporate engagement tomorrow. The models for this engagement are still embryonic, but given what is at stake, they represent an exciting and important vein for future research.

\section{References}

Allen, J. A. (2003). Virtual Water-the Water, Food, and Trade Nexus: Useful Concept or Misleading Metaphor? Water International, 28(1), 106-112. http://dx.doi.org/10.1080/02508060.2003.9724812

Auster, E. R. (1994). Macro and strategic perspectives on interorganizational linkages: A comparative analysis and review with suggestions for reorientation. In P. Shrivastava, A. S. Huff, \& J. E. Dutton (Eds.), Advances in Strategic Management (Vol. 10, pp. 3-40). USA: JAI Press.

Baker, W., \& Toft, S. (2003). A framework methodology for estimating the impact of household metering on consumption Main report (Vol. 1). UK: UK Water Industry Research Limited.

Barringer, B. R., \& Harrison, J. S. (2000). Walking a tightrope: Creating value through interorganizational relationships. Journal of Management, 26(3), 367-403. http://dx.doi.org/10.1177/014920630002600302

Barton, B. (2010). Murky Waters? Corporate Reporting on Water Risk. Boston, MA: Ceres.

Brown, H. S., de Jong, M., \& Levy, D. L. (2009). Building institutions based on information disclosure: lessons from GRI's sustainability reporting. Journal of Cleaner Production, 17(6), 571-580. http://dx.doi.org/10.1016/j.jclepro.2008.12.009

Butler, D., \& Memon, F. A. (2006). Water Demand Management. UK: IWA Publishing.

Carroll, A. B. (1979). A three-dimensional conceptual model of corporate performance. Academy of Management Review, 4(4), 497-505. http://dx.doi.org/10.5465/AMR.1979.4498296

CDP. (n.d.). Become a CDP Investor Signatory. Carbon Disclosure Project.

CDP. (2011). CDP Water Disclosure Global Report 2011 (Vol. 2). UK: Carbon Disclosure Project. Retrieved from https://www.cdproject.net/CDPResults/CDP-Water-Disclosure-Global-Report-2011.pdf

CDP. (2012). CDP Water Disclosure Global Report 2011 (Vol. 3). UK: Carbon Disclosure Project. Retrieved from https://www.cdproject.net/CDPResults/CDP-Water-Disclosure-Global-Report-2011.pdf

CDP. (2013). CDP Water Disclosure Global Report 2012 (Vol. 4). UK: Carbon Disclosure Project. Retrieved from https://www.cdproject.net/CDPResults/CDP-Water-Disclosure-Global-Report-2011.pdf

Chapagain, A. K., Hoekstra, A. Y., Savenije, H. H. G., \& Gautam, R. (2006). The water footprint of cotton consumption: An assessment of the impact of worldwide consumption of cotton products on the water resources in the cotton producing countries. Ecological Economics, 60(1), 186-203. http://dx.doi.org/10.1016/j.ecolecon.2005.11.027

Clark, G. L., \& Hebb, T. (2005). Why should they care? The role of institutional investors in the market for corporate global responsibility. Environment and Planning A, 37(11), 2015. http://dx.doi.org/10.1068/a38116

Daniel, M., \& Sojamo, S. (2012). From Risks to Shared Value? Corporate Strategies in Building a Global Water Accounting and Disclosure Regime. Water Alternatives, 5(3), 636-657.

DiMaggio, P., \& Powell, W. W. (1983). The iron age revisited: Institutional isomorphism and collective rationality in organizational fields. American Sociological Review, 48, 147-160. 
Dobbs, R., \& Pohl, H. (2013). Infrastructure Productivity: How to save \$1 trillion a year (Vol. 1). USA: McKinsey Global Institute.

Elg, U. (2000). Firms Home-Market Relationships: Their Role when Selecting International Alliance Partners. Journal of International Business Studies, 31(1), 169-177. http://dx.doi.org/10.1057/palgrave.jibs.8490895

Gerbens-Leenes, P. W., \& Hoekstra, A. Y. (2008). Business water footprint accounting: A tool to assess how production of goods and services impacts on freshwater resources worldwide (Vol. 27). The Netherlands: UNESCO-IHE Institute for Water Education.

Giddens, A. (1984). The constitution of society: introduction of the theory of structuration (Vol. 1). USA: Univ of California Press.

Global Reporting Initiative. (2011). G3.1 Sustainability Reporting Guidlines. GRI.

Goes, J. B., \& Park, S. H. (1997). Interorganizational links and innovation: The case of hospital services. Academy of Management Journal, 40(3), 673-696. http://dx.doi.org/10.2307/257058

Harrigan, K. R., \& Newman, W. H. (1990). Bases of interorganisation co-operation: propensity, power, persistence. Journal of Management Studies, 27(4), 417-434. http://dx.doi.org/10.1111/j.1467-6486.1990.tb00255.x

Hebb, T. (2008). No small change: Pension Funds and corporate engagement (Vol. 1). USA: Cornell University Press.

Hepworth, N., \& Orr, S. (2013). Corporate Water Stewardship. In B. A. Lankford, K. Bakker, M. Zeitoun, \& D. Conway (Eds.), Water Security: Principles, Perspectives and Practices (1st ed., p. 221). Routledge.

Hillman, A. J., Cannella, A. A., \& Paetzold, R. L. (2000). The resource dependence role of corporate directors: Strategic adaptation of board composition in response to environmental change. Journal of Management Studies, 37(2), 235-256. http://dx.doi.org/10.1111/1467-6486.00179

Hillman, A. J., Withers, M. C., \& Collins, B. J. (2009). Resource dependence theory: A review. Journal of Management, 35(6), 1404-1427. http://dx.doi.org/10.1177/0149206309343469

Hoekstra, A. Y., \& Chapagain, A. K. (2008). Globalization of water: sharing the planet's freshwater resources (Vol. 1). UK: Wiley Blackwell. http://dx.doi.org/10.1002/9780470696224.ch1

Howell, L. (2012). Global Risks 2012 (Vol. 7). Switzerland: World Economic Forum.

Howell, L. (2013). Global Risks 2013 (Vol. 8). Switzerland: World Economic Forum.

IMF. (2013). World Economic Outlook 2013: Hopes, Realities, Risks (Vol. HC10.80). USA: International Monetary Fund Publication Services.

Kostova, T., Roth, K., \& Dacin, M. T. (2008). Institutional theory in the study of multinational corporations: A critique and new directions. Academy of Management Review, 33(4), 994-1006. http://dx.doi.org/10.5465/AMR.2008.34422026

Levy, D. L., \& Newell, P. J. (2005). A neo-Gramscian approach to business in international environmental politics: an interdisciplinary, multi-level framwork. In D. L. Levy \& P. J. Newell (Eds.), The Business of Global Environmental Governance (Vol. 1, pp. 47-69). MIT Press.

Mandate, C. E. O. W. (2013). Mission Statement. UN Global Compact.

Meyer J., C. K. (2010). Leadership in the Age of Transparency. Harvard Business Review, 88(4), 38-46.

Meyer, J. W., \& Rowan, B. (1977). Institutionalized organizations: Formal structure as myth and ceremony. American Journal of Sociology, 83(2), 340-363. http://dx.doi.org/10.2307/2778293

Morrison, J., Schulte, P., \& Schenck, R. (2010). Corporate Water Accounting: An Analysis of Methods and Tools for Measuring Water Use and its Impacts (Vol. 1). USA: Pacific Institute.

Murray, J. Y., Kotabe, M., \& Zhou, J. N. (2004). Strategic alliance-based sourcing and market performance: evidence from foreign firms operating in China. Journal of International Business Studies, 36(2), 187-208. http://dx.doi.org/10.1057/palgrave.jibs. 8400120

OECD. (2006). Infrastructure to 2030: Telecom, Land Transport, Water and Electricity (Vol. 1). France: OECD Publishing.

Oliver, C. (1990). Determinants of interorganizational relationships: Integration and future directions. Academy of Management Review, 15(2), 241-265. http://dx.doi.org/10.5465/AMR.1990.4308156 
Oliver, C. (1997). Sustainable competitive advantage: Combining institutional and resource-based views. $\begin{array}{llll}\text { Strategic Management } & \text { Journal, }\end{array}$ http://dx.doi.org/10.1002/(SICI)1097-0266(199710)18:9<697::AID-SMJ909>3.0.CO;2-C

Orr, S., \& Cartwright, A. (2010). Water Scarcity Risks: Experience of the Private Sector. In L. Martinez-Cortina, A. Garrido, \& E. Lopez-Gunn (Eds.), Re-thinking Water and Food Security (Vol. 1). CRC Press.

Peloza, J. (2009). The Challenge of Measuring Financial Impacts From Investments in Corporate Social Performance. Journal of Management, 35(6), 1518-1541. http://dx.doi.org/10.1177/0149206309335188

Pfeffer, J., \& Salancik, G. R. (1978). The external control of organizations: A resource dependence perspective (Vol. 1). USA: Harper \& Row.

Pittock, J., \& Lankford, B. A. (2010). Environmental Water Requirements: demand management in an era of water scarcity. Journal of Integrative Environmental Sciences, 7(1), 75-93. http://dx.doi.org/10.1080/19438151003603159

Postel, S. L. (2000). Entering an era of water scarcity: the challenges ahead. Ecological Applications, 10(4), 941-948. http://dx.doi.org/10.1890/1051-0761(2000)010[0941:EAEOWS]2.0.CO;2

Provan, K. G., \& Gassenheimer, J. B. (1994). Supplier Commitment in Relational Contract Exchanges with Buyers: A Study of Interorganisational Dependence and Exercised Power. Journal of Management Studies, 31(1), 55-68. http://dx.doi.org/10.1111/j.1467-6486.1994.tb00332.x

Rao, H., \& Sivakumar, K. (1999). Institutional sources of boundary-spanning structures: The establishment of investor relations departments in the Fortune 500 industrials. Organization Science, 10(1), 27-42. http://dx.doi.org/10.1287/orsc.10.1.27

Sarni, W. (2011). Corporate Water Strategies (Vol. 1, p. 224). UK: Earthscan.

Scott, W. R., \& Meyer, J. W. (1994). Institutional environments and organizations: Structural complexity and individualism (Vol. 1). USA: Sage Publications, Inc.

Seckler, D., Barker, R., \& Amarasinghe, U. (1999). Water scarcity in the twenty-first century. International Journal of Water Resources Development, 15(1-2), 29-42. http://dx.doi.org/10.1080/07900629948916

Selznick, P. (1949). TVA and the grass roots: A study in the sociology of formal organization (Vol. 3). USA: Univ of California Press.

Skinner, S. J., Donnelly, J. H., \& Ivancevich, J. M. (1987). Effects of transactional form on environmental linkages and power-dependence relations. The Academy of Management Journal, 30(3), 577-588. http://dx.doi.org/10.2307/256016

Stearns, T. M., Hoffman, A. N., \& Heide, J. B. (1987). Performance of commercial television stations as an outcome of interorganizational linkages and environmental conditions. Academy of Management Journal, 30(1), 71-90. http://dx.doi.org/10.2307/255896

Thompson, J. D., \& McEwen, W. J. (1958). Organizational goals and environment: Goal-setting as an interaction process. American Sociological Review, 23(1), 23-31.

Ulrich, D., \& Barney, J. B. (1984). Perspectives in Organizations: Resource Dependence, Efficiency, and Population. Academy of Management Review, 9(3), 471-481. http://dx.doi.org/10.5465/AMR.1984.4279680

Waughray, D. (2011). Water security: the water-energy-food climate nexus (Vol. 1). USA: World Economic Forum.

WBCSD. (2013). Sharing Water: Engaging Business (Vol. 1). Switzerland: World Business Council for Sustainable Development.

WRG. (2013). About the 2030 Water Resources Group. 2030 Water Resources Group.

Zald, M. N. (1969). The power and functions of boards of directors: A theoretical synthesis. American Journal of Sociology, 75(1), 97-111. 


\section{Copyrights}

Copyright for this article is retained by the author(s), with first publication rights granted to the journal.

This is an open-access article distributed under the terms and conditions of the Creative Commons Attribution license (http://creativecommons.org/licenses/by/3.0/). 